\title{
Highly Nonlinear Gallium Nitride Waveguides
}

Stassen, Erik; Pu, Minhao; Semenova, Elizaveta; Zavarin, E.; Lundin, W.; Yvind, Kresten

Published in:

Proceedings of 2018 Conference on Lasers and Electro-Optics (CLEO)

Link to article, DOI:

10.1364/CLEO_SI.2018.STh3I.1

Publication date:

2018

Document Version

Peer reviewed version

Link back to DTU Orbit

Citation (APA):

Stassen, E., Pu, M., Semenova, E., Zavarin, E., Lundin, W., \& Yvind, K. (2018). Highly Nonlinear Gallium Nitride Waveguides. In Proceedings of 2018 Conference on Lasers and Electro-Optics (CLEO) (pp. 1-2). Optical Society of America. https://doi.org/10.1364/CLEO_SI.2018.STh3l.1

\section{General rights}

Copyright and moral rights for the publications made accessible in the public portal are retained by the authors and/or other copyright owners and it is a condition of accessing publications that users recognise and abide by the legal requirements associated with these rights.

- Users may download and print one copy of any publication from the public portal for the purpose of private study or research.

- You may not further distribute the material or use it for any profit-making activity or commercial gain

- You may freely distribute the URL identifying the publication in the public portal 


\title{
Highly Nonlinear Gallium Nitride Waveguides
}

\author{
E. Stassen ${ }^{1}$, M. Pu ${ }^{1}$, E. Semenova ${ }^{1}$, E. Zavarin ${ }^{2}$, W. Lundin ${ }^{2}$, and K. Yvind ${ }^{1}$ \\ 1. DTU Fotonik, Technical University of Denmark, Ørsteds Plads 345A, 2800 Kgs. Lyngby, Denmark \\ 2. Ioffe Institute, Politekhnicheskaya str. 26, 194021 St. Petersburg, Russia; \\ ersta@fotonik.dtu.dk
}

\begin{abstract}
We demonstrate a high effective nonlinearity in high refractive-index-contrast gallium nitride waveguides by performing four-wave mixing characterization. The intrinsic material nonlinearity (n2) of gallium nitride is extracted at telecom wavelengths. (C) 2018 The Author(s) OCIS codes:(190.4390) Nonlinear optics, integrated optics; 190.4380) Nonlinear optics, four-wave mixing.
\end{abstract}

Gallium nitride $(\mathrm{GaN})$ is a potential good candidate for integrated nonlinear optics, owing to a large bandgap $(3.4 \mathrm{eV})$, large intrinsic nonlinearities (both $\chi^{(2)}$ and $\left.\chi^{(3)}\right)$ and excellent thermal properties [1]. However, there are only a few investigations on nonlinear phenomena in the integrated $\mathrm{GaN}$ platform [2]. Here we present a systematic study of four-wave mixing in high confinement $\mathrm{GaN}$ waveguides and extract the intrinsic nonlinearity $\left(\mathrm{n}_{2}\right)$ at telecom wavelengths for the first time.

A 700-nm thick GaN film was grown on sapphire in the Dragon-125 MOVPE system using a low-temperature GaN nucleation layer annealed under $\mathrm{H}_{2}$-free ambient for promoting planar growth of the thin layer. Hereafter, waveguides were patterned using e-beam lithography in HSQ resist, and etched in a chlorine-based ICP-RIE. Finally the devices are clad with $250 \mathrm{~nm}$ ALD and $2000 \mathrm{~nm}$ e-beam evaporated $\mathrm{Al}_{2} \mathrm{O}_{3}$, which ensures good thermal properties and a refractive index match with the substrate. The cross-section dimension of the waveguides under investigation is $700 \times 800 \mathrm{~nm}^{2}$, which ensures single mode operation. Fig. 1(a) shows the calculated dispersion for the waveguide. The waveguide is tapered to $4 \mu \mathrm{m}$ at both sample facets for a better chip-to-fiber coupling efficiency and angled 16 deg to reduce reflections. Fig. 1(b) shows a cross-sectional view of the fabricated GaN waveguide at the sample facet.

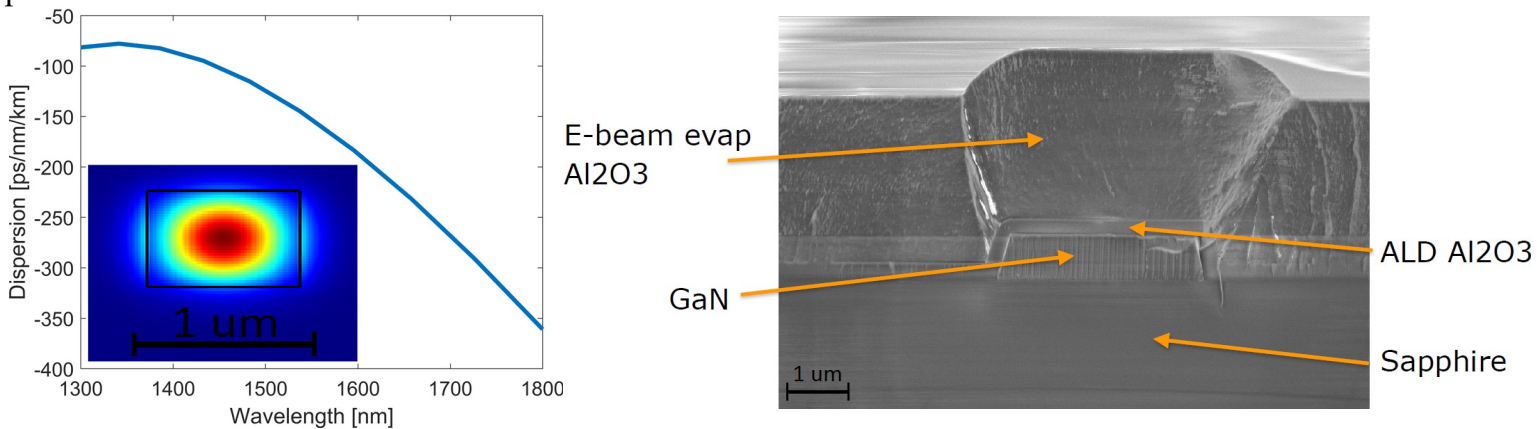

Fig.1 GaN waveguides: (a) Dispersion. Insert: mode profile, (b) Cross sectional view of coupling taper out region.

The insertion loss is shown in fig. 2a and is seen to be flat all the way up to a coupled power of $24 \mathrm{dBm}$ (coupling loss $4 \mathrm{~dB}$ ), in accordance with the large bandgap of GaN. Next to it, in fig. $2 \mathrm{~b}$ the transmission spectrum is shown, which is seen to vary by up to $5 \mathrm{~dB}$ which is indicative of some scattering processes in the waveguide, which are probably due to fabrication imperfections such as sidewall roughness and local defects.

The conversion efficiency (CE) has been measured for a $9 \mathrm{~mm}$ long device versus coupled pump power and is shown in fig. 3a. The signal power was $12 \mathrm{dBm}$. Assuming no pump depletion (valid for the low CE's observed here) an effective nonlinearity $\gamma=8 \mathrm{~W}^{-1} \mathrm{~m}^{-1}$ is found fitting the following equation [3] to the data.

$$
\eta=\frac{P_{\text {idler }(L)}}{P_{\text {signal }(L)}}=\left(\gamma P_{\text {pump }}(0) L_{\text {eff }}\right)^{2}
$$

where $L_{\text {eff }}=\left(1-e^{-\alpha L}\right) / \alpha$ (the propagation loss is estimated from the round trip loss of rings and the cut-back method to be around $3.5 \mathrm{~dB} / \mathrm{cm}$ ). Since the chip conversion efficiency is rather low and the pump to signal spacing is small for this experiment, four-wave mixing in the several meters of fiber in the setup contributed around $10-20 \%$ of the observed idler. Therefore, for all the measurements, a reference measurement with only fiber-to-fiber coupling (no chip) was made, where the distance between the lensed fibers was adjusted such that the IL matched that of the chip. This made it possible to measure the idler power generated only by the fiber, which could then be subtracted from the idler power generated when the chip was inserted, to give the idler generated by only the chip. 

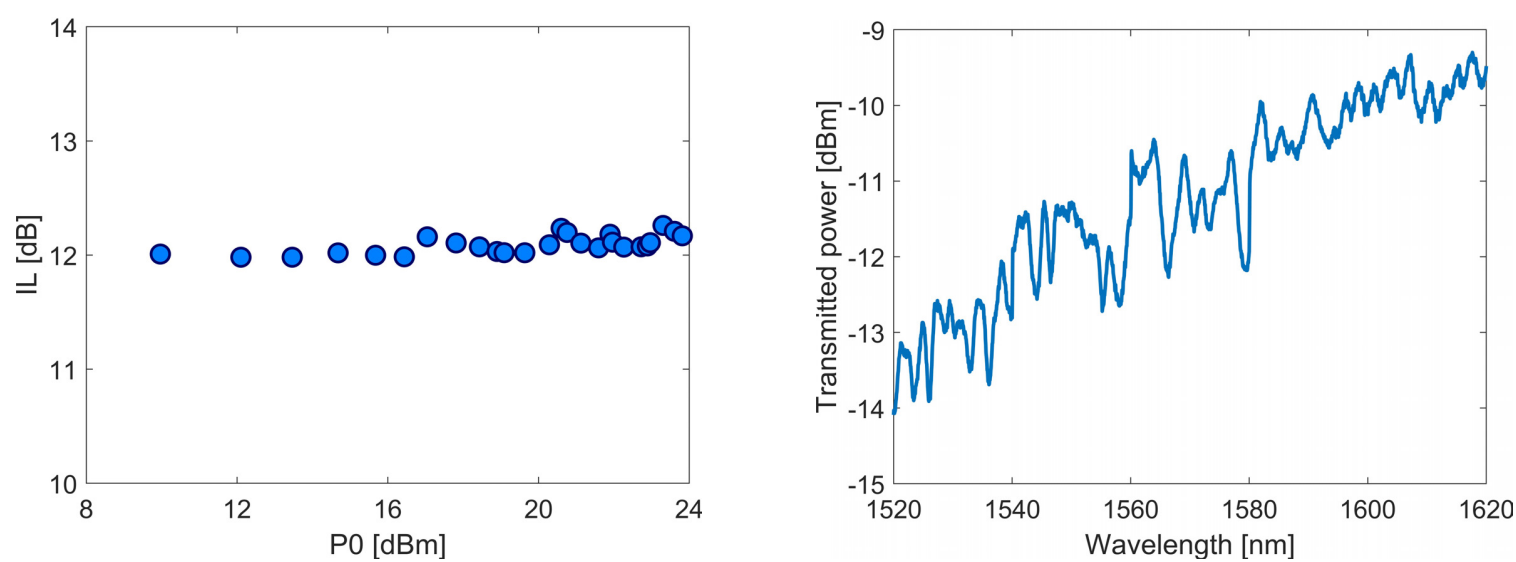

Fig.2 GaN waveguides linear properties: (a) Total insertion loss (IL) vs. input power at $1560 \mathrm{~nm}$. (b) Transmission spectrum of the waveguide at $1 \mathrm{dBm}$ input power.

From the measured effective nonlinearity the material nonlinearity was extracted via the relation $\gamma=$ $2 \pi n_{2} / \lambda A_{\text {eff }}$ yielding $\mathrm{n}_{2}=7.8 \times 10^{-19} \mathrm{~m}^{2} \mathrm{~W}^{-1}$ which is comparable to values previously obtained for GaN thin films at visible wavelengths [4], and is higher than several other popular nonlinear platforms, cementing the promise of GaN for integrated nonlinear photonics.

The very small dispersion and short device length ensures relatively broadband conversion efficiency of the waveguides, see fig. 3b. The relatively large variations in CE can partly be explained from the transmission spectrum, where there is noticeable variation in the spectrum probably due to fabrication imperfections. Integrated $\mathrm{THz}$ ring resonators with intrinsic Q's of $10^{5}$ and dimensions $700 \mathrm{~nm} \times 1250 \mathrm{~nm}$ for anomalous dispersion were also fabricated and the threshold for OPO in a critically coupled resonator can be calculated from the equation [5] $\mathrm{P}_{\mathrm{th}}=2 \pi^{2} n^{2} \frac{L A_{e f f}}{n_{2} \lambda} \frac{1}{Q^{2}}$ yielding a threshold power of $1.4 \mathrm{~W}$ (bus coupled power). Further improvement in $\mathrm{Q}$ will lower this and already for $\mathrm{Q}=266000$ the threshold for $\mathrm{OPO}$ is reduced to $200 \mathrm{~mW}$, with further reduction as the losses are lowered even more.
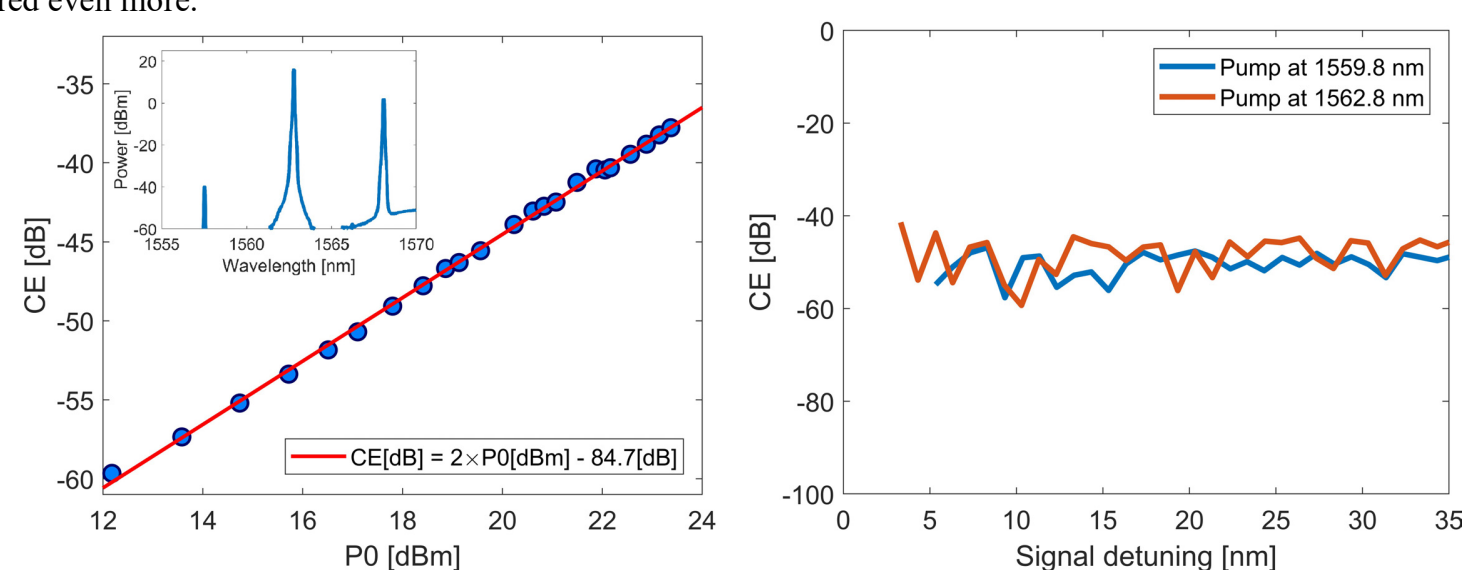

Fig. $3 \mathrm{GaN}$ waveguides nonlinear properties: (a) $\mathrm{CE}$ vs $\mathrm{P}_{0}$ (pump power at the start of the waveguide). Insert: Four-wave mixing spectrum (b) CE vs signal detuning.

Acknowledgements: DNRF Centre project SPOC (ref. DNRF123).

\section{References}

[1] S. Pezzagna, J. Brault, M. de Micheli, P. Vennéguès, A.D. Wieck, J. Massies "GaN, a new material for integrated nonlinear optics," Proc. of ECIO 2007, 25(2007)

[2] C. Xiong, W. Pernice, K. Ryu, C. Schuck, K. Fong, T. Palacios and H. Tang, ’Integrated GaN photonic circuits on silicon (100) for second harmonic generation" Optics Express.19, 10462 (2011).

[3] M. Pu et al., "Efficient frequency comb generation in AlGaAs-on-insulator," Optica 3823 (2016).

[4] E. Fazio et al. "Measurement of pure Kerr nonlinearity in GaN thin films at $800 \mathrm{~nm}$ by means of eclipsing Z-scan experiments." Journal of Optics A: Pure and Applied Optics 9.2: L3 (2007).

[5] A. B. Matsko., et al. "Optical hyperparametric oscillations in a whispering-gallery-mode resonator: Threshold and phase diffusion." Physical Review A 71.3: 033804. (2005) 